\title{
Differential Nicotinic Modulation of Glutamatergic and GABAergic VTA Microcircuits
}

\author{
Yijin Yan, ${ }^{2}$ Nicole A. Beckley, ${ }^{1,2}{ }^{-}$Veronica J. Kim, ${ }^{2}$ and ${ }^{(}$Ryan M. Drenan ${ }^{1,2}$
}

https://doi.org/10.1523/ENEURO.0298-19.2019

${ }^{1}$ Department of Physiology and Pharmacology, Wake Forest University School of Medicine, Winston-Salem, North Carolina 27101 and ${ }^{2}$ Department of Pharmacology, Northwestern University Feinberg School of Medicine, Chicago, Illinois 60611

\begin{abstract}
Ventral tegmental area (VTA) neurons receive glutamatergic and/or GABAergic input from other local neurons within the VTA. Nicotinic acetylcholine receptor (nAChR) activity is capable of modulating such intra-VTA transmission, but the mechanisms are unclear. Here, we isolated monosynaptic glutamate or GABA transmission from mouse medial VTA (mVTA) to lateral VTA (latVTA) using pharmacology and optogenetics, and we studied the ability of nicotine to modulate these modes of transmission. The action of nicotine on MVTA to latVTA glutamate transmission was bidirectional; nicotine enhanced glutamate release in half of the recorded latVTA cells and inhibited release in the other half. Nicotine-mediated reduction in glutamate release was reversed by blockade of $\mathrm{GABA}_{\mathrm{A}}$ receptors. This, coupled with expression data demonstrating coexpression of vesicular glutamate transporter 2 (VGluT2) and glutamate decarboxylase 2 (Gad2) in mVTA neurons, suggests that nicotine is able to stimulate GABA corelease from mVTA VGluT2 ${ }^{+}$neurons. Nicotine had an altogether different effect on mVTA to latVTA GABA release from Gad2 ${ }^{+}$cells; nicotine suppressed GABA release from $\mathrm{mVTA}$ Gad2 ${ }^{+}$terminals in nearly all cells tested. Together, these data uncover a complex system of local circuitry in the VTA that is modulated by nAChR activity. These actions of nicotine, which occurred at concentrations of nicotine found in the artificial CSF of cigarette smokers, may play a role in the adaptive response of the reward system to repeated nicotine exposure.
\end{abstract}

Key words: nicotinic acetylcholine receptor; dependence; VTA; glutamate; GABA; tobacco

\section{Significance Statement}

This study uncovers novel aspects of nicotinic acetylcholine receptor neuropharmacology and ventral tegmental area (VTA) neurobiology that have implications for understanding nicotine dependence mechanisms. Nicotine must interact with receptors and circuits in VTA to cause dependence, and this study advances our understanding of specific nicotine-sensitive circuits that reside within this brain area. Identifying these novel nicotine-sensitive systems could provide new/additional mechanisms for targeting with smoking cessation drugs or therapeutic agents. Our results also add new details to the conceptual framework associated with reward circuit wiring, which could lead to an improved mechanistic understanding of natural reward processing.

\section{Introduction}

Tobacco addiction is the leading cause of preventable death (Centers for Disease Control and Prevention, 2018).

Received July 31, 2019; accepted October 30, 2019; First published November 19, 2019.

The authors declare no competing financial interests.
Although smoking rates in the United States declined from 2005 to 2017, electronic cigarette usage has increased, which may promote relapse to traditional ciga- 
rette smoking (Young-Wolff et al., 2018). Smoking cessation medications are not sufficiently effective at fostering cessation, and a better understanding of the mechanisms of nicotine dependence could lead to novel and/or more efficacious pharmacological treatment approaches.

The ventral tegmental area (VTA) is a key structure in dopamine (DA) reward circuitry, and the interaction of nicotine with VTA components is a necessary, though not sufficient, condition for nicotine dependence. Rodent models have provided substantial insight into this interaction. For example, nicotine intravenous self-administration in the rat requires functional activity of nicotinic acetylcholine receptors (nAChRs) in VTA neurons (Corrigall et al., 1994). Mice lacking the $\beta 2 \mathrm{nAChR}$ are insensitive to the dopamine-stimulating and reinforcing action of nicotine (Picciotto et al., 1995, 1998), and re-expression of $\beta 2$ subunits into the VTA of these mice restores nicotine modulation of VTA neuron activity and nicotine selfadministration behavior (Maskos et al., 2005). Mansvelder and McGehee (2000) and Mansvelder et al. (2002) first indicated the potential for intra-VTA circuitry in the action of nicotine by showing that presynaptic $\alpha 7$ - and $\beta 2$ containing nAChRs mediate nicotine-stimulated glutamate and GABA release, respectively, onto VTA neurons. These data, coupled with a prior demonstration that VTA GABAergic neurons locally inhibit DA cells (Johnson and North, 1992a,b), helped to establish a framework to explain the direct and indirect modulation by nicotine of VTA DA neuron output.

DA, long known to be involved in natural reward and motivation to seek drugs of abuse (Lüscher and Malenka, 2011), is not the only neurotransmitter released from VTA neurons. The aforementioned VTA GABAergic neurons (1) locally inhibit VTA DA neurons (Johnson and North, 1992b; Tan et al., 2012), and (2) send long-range inhibitory projections to target structures such as nucleus accumbens (NAc; van Zessen et al., 2012) and lateral habenula (Root et al., 2014b). nAChRs, which are functionally expressed on VTA GABA neurons (Yan et al., 2018), play an important role in shaping the rewarding response to nicotine (Tolu et al., 2013; Ngolab et al., 2015). VTA DA neurons also receive asymmetric (i.e., excitatory) synaptic inputs from local glutamatergic neurons in the VTA (Dobi et al., 2010). These glutamatergic cells, which are defined by active expression of the vesicular glutamate transporter 2 (VGluT2), can directly stimulate VTA DA neurons to promote reward-like behavior (Wang et al., 2015). These various VTA cell types show preferential localization in medial VTA (mVTA) versus lateral VTA (latVTA). VTA GABAergic neurons, and especially glutamatergic neu-

This research was supported by Department of Health and Human Services I National Institutes of Health I National Institute on Drug Abuse Grant DA035942 to R.M.D.

Correspondence should be addressed to Ryan $M$. Drenan at Rdrenan@wakehealth.edu.

https://doi.org/10.1523/ENEURO.0298-19.2019

Copyright (C) 2019 Yan et al.

This is an open-access article distributed under the terms of the Creative Commons Attribution 4.0 International license, which permits unrestricted use, distribution and reproduction in any medium provided that the original work is properly attributed. rons, are more likely to be found in mVTA (Hnasko et al., 2012; Root et al., 2014a,b; Ntamati and Lüscher, 2016; Qi et al., 2016; Yoo et al., 2016), whereas classical DAergic neurons are more abundant in latVTA (Lammel et al., 2008; Yan et al., 2018).

We recently demonstrated that $\beta 2$-containing $\mathrm{nAChRs}$ are functionally expressed on VTA VGluT2 ${ }^{+}$neurons (Yan et al., 2018). Gene-editing experiments, corroborated by pharmacological data, suggest that nicotine activationnot desensitization - of those receptors drives excitatory transmission in nearby/local VTA neurons (Yan et al., 2018). However, questions remain regarding cholinergic receptor modulation of local VTA glutamatergic and GABAergic microcircuits. For example, it is unknown whether nAChRs are situated on presynaptic terminals to directly modulate fast transmitter release onto local VTA cells, or whether nAChRs act in a more indirect, polysynaptic manner. In this study, we examined glutamate and GABA transmission in local VTA circuits by expressing channelrhodopsin 2 (ChR2) in mVTA VGluT2 ${ }^{+}$or glutamate decarboxylase 2-positive $\left(\mathrm{Gad} 2^{+}\right)$cells followed by recording optically evoked excitatory or inhibitory postsynaptic currents in latVTA. The ability of nicotine to modulate these circuits was examined, permitting a more detailed picture of cholinergic modulation in VTA microcircuits to emerge.

\section{Materials and Methods}

\section{Materials and viral vectors}

Dihydro- $\beta$-erythroidine hydrobromide $(\mathrm{DH} \beta \mathrm{E})$, methyllycaconitine (MLA), picrotoxin (PTX), atropine sulfate (atropine), and 4-aminopyridine (4-AP) were obtained from Sigma-Aldrich. 6-Cyano-7-nitroquinoxaline-2,3-dione (CNQX), and D(-)-2-amino-5-phosphonopentanoic acid (D-AP5) were obtained from Tocris Bioscience. QX314 chloride (QX314) was from EMD-Millipore. Tetrodotoxin (TTX) was obtained from Abcam. Nicotine hydrogen tartrate salt was obtained from Glentham Life Sciences. AAV5.EF1a.DIO.hChR2(H134R)-eYFP.WPRE.hGH was obtained from Addgene.

\section{Mice}

All experimental protocols involving mice were reviewed and approved by an institutional animal care and use committee. Procedures also followed the guidelines for the care and use of animals provided by the National Institutes of Health Office of Laboratory Animal Welfare. All efforts were made to minimize animal distress and suffering during experimental procedures, including during the use of anesthesia. Mice were housed at $22^{\circ} \mathrm{C}$ on a $12 \mathrm{~h}$ light/dark cycle with food and water available ad libitum. Mice were weaned on postnatal day 21 and housed with same-sex littermates. A tail sample was taken from each mouse for genotyping via PCR. The following mouse strains were obtained from The Jackson Laboratory: VGLUT2-IRES-Cre (stock \#016963); and GAD2-IRES-Cre (stock \#010802). Male and female mice were used in approximately equal numbers. 


\section{Stereotaxic surgery}

Male and female mice were used for surgery starting at 8 weeks of age. Mice were initially anesthetized with an intraperitoneal injection of a ketamine/xylazine mixture (120 mg/kg ketamine, $16 \mathrm{mg} / \mathrm{kg}$ xylazine). Mice were given additional "boost" injections of ketamine $(100 \mathrm{mg} /$ $\mathrm{kg}$, i.p.) as needed. Alternatively, some mice were anesthetized with isoflurane: $3 \%$ (flow rate, $500 \mathrm{ml} / \mathrm{min}$ ) for induction, and $1.5 \%$ (flow rate, $28 \mathrm{ml} / \mathrm{min}$ ) for maintenance. Mice were secured into a stereotaxic frame, and a small incision at the top of the head was made to expose the skull. Coordinates (unilateral) used for mVTA injections were as follows (relative to bregma, in $\mathrm{mm}$ ): mediolateral, +0.01 (or -0.01); anteroposterior (AP), -3.2; dorsoventral (DV), -4.55 . Exact coordinates were adjusted to account for slight differences in the head size of individual mice: the bregma/lambda distance measured for each mouse was divided by the reported bregma/lambda distance for C57 background mice (4.21), then multiplied by the AP coordinate. The injection needle was slowly lowered through the drilled hole to the DV coordinate. For adenoassociated viruses (AAVs), $500 \mathrm{nl}$ of virus was infused at a rate of $50 \mathrm{nl} / \mathrm{min}$. For all stereotaxic injections, the injection needle was left in place for 10 min after the infusion ended before slowly retracting the needle. Sutures were used to close the incision. At the conclusion of the surgery, mice were given ketoprofen (5 mg/kg, s.c.), placed in a recovery cage, kept warm, and observed until they were ambulatory. Mice were single housed following virus injection surgery and were given at least $14 \mathrm{~d}$ to recover and for the virus to express before beginning experimental procedures. For electrophysiology experiments, accurate targeting of the VTA was determined via direct visualization of fluorescent neurons in brain slices during recordings.

\section{Immunohistochemistry and confocal microscopy}

Mice were anesthetized with sodium pentobarbital (200 $\mathrm{mg} / \mathrm{kg}$, i.p.) and transcardially perfused with $30 \mathrm{ml}$ of PBS followed by $30 \mathrm{ml}$ of $4 \%$ paraformaldehyde. Brains were dissected and postfixed in $4 \%$ paraformaldehyde overnight at $4^{\circ} \mathrm{C}$. Coronal brain slices $(50 \mu \mathrm{m})$ were cut on a freezing sliding microtome (SM2010R; Leica). VTAcontaining slices were stained using the following procedure. Slices were first permeabilized for 2 min via incubation in PBST (0.3\% Triton X-100 in PBS), followed by a $60 \mathrm{~min}$ incubation in blocking solution [0.1\% Triton $X-100,5 \%$ horse serum in Tris-buffered saline (TBS)]. The primary antibodies used in this study were as follows: sheep anti-TH (catalog \#AB1542; Millipore), rabbit antiGFP (catalog \#A11122; Thermo Fisher Scientific). Primary antibodies were diluted in blocking solution (anti-TH at 1:1000, anti-GFP at 1:500). Slices were incubated in primary antibodies overnight at $4^{\circ} \mathrm{C}$. Three $10 \mathrm{~min}$ washes in TBST (0.1\% Triton X-100 in TBS) were performed before transferring slices to secondary antibodies for a $60 \mathrm{~min}$ incubation at room temperature (donkey anti-sheep Alexa Fluor 647; chicken anti-rabbit Alexa Fluor 488, diluted to 1:500 in blocking solution). Slices were washed as before, mounted on slides, and coverslipped with VECTASHIELD.

\section{Brain slice preparation and recording solutions}

Mice were anesthetized with Euthasol (sodium pentobarbital, $100 \mathrm{mg} / \mathrm{kg}$; sodium phenytoin, $12.82 \mathrm{mg} / \mathrm{kg}$ ) before transcardiac perfusion with an oxygenated $(95 \%$ $\mathrm{O}_{2} / 5 \% \quad \mathrm{CO}_{2}$ ), $4^{\circ} \mathrm{C} \mathrm{N}$-methyl-D-glucamine (NMDG)-based recovery solution that contains the following (in $\mathrm{mM}$ ): 93 NMDG, $2.5 \mathrm{KCl}, 1.2 \mathrm{NaH}_{2} \mathrm{PO}_{4}, 30 \mathrm{NaHCO}_{3}, 20$ HEPES, 25 glucose, 5 sodium ascorbate, 2 thiourea, 3 sodium pyruvate, $10 \mathrm{MgSO}_{4} \cdot 7 \mathrm{H}_{2} \mathrm{O}$, and $0.5 \mathrm{CaCl}_{2} \cdot 2 \mathrm{H}_{2} \mathrm{O}$, at $300-310$ mOsm and $\mathrm{pH}$ 7.3-7.4. Brains were immediately dissected after the perfusion and held in an oxygenated $4^{\circ} \mathrm{C}$ recovery solution for 1 min before cutting a brain block containing the VTA and sectioning the brain with a vibratome (VT1200S; Leica). Coronal slices (200-250 $\mu \mathrm{m})$ were sectioned through the VTA and transferred to an oxygenated $33^{\circ} \mathrm{C}$ recovery solution for $12 \mathrm{~min}$. Slices were then kept in holding solution containing the following (in mM): $92 \mathrm{NaCl}, 2.5 \mathrm{KCl}, 1.2 \mathrm{NaH}_{2} \mathrm{PO}_{4}, 30 \mathrm{NaHCO}_{3}, 20$ HEPES, 25 glucose, 5 sodium ascorbate, 2 thiourea, 3 sodium pyruvate, $2 \mathrm{MgSO}_{4} \cdot 7 \mathrm{H}_{2} \mathrm{O}$, and $2 \mathrm{CaCl}_{2} \cdot 2 \mathrm{H}_{2} \mathrm{O}$, at 300-310 mOsm and $\mathrm{pH} 7.3-7.4$ for $\geq 60 \mathrm{~min}$ before recordings. Brain slices were transferred to a recording chamber ( $1 \mathrm{ml}$ volume) being continuously superfused at a rate of $1.5-2.0 \mathrm{ml} / \mathrm{min}$ with oxygenated $32^{\circ} \mathrm{C}$ recording solution. The recording solution contained the following (in mM): $124 \mathrm{NaCl}, 2.5 \mathrm{KCl}, 1.2 \mathrm{NaH}_{2} \mathrm{PO}_{4}, 24 \mathrm{NaHCO}_{3}$, 12.5 glucose, $2 \mathrm{MgSO}_{4} \cdot 7 \mathrm{H}_{2} \mathrm{O}$, and $2 \mathrm{CaCl}_{2} \cdot 2 \mathrm{H}_{2} \mathrm{O}$, at 300-310 mOsm and $\mathrm{pH}$ 7.3-7.4. For all recordings, the recording solution was supplemented with $1 \mu \mathrm{M}$ atropine to eliminate contributions from muscarinic ACh receptors. Patch pipettes were pulled from borosilicate glass capillary tubes (1B150F-4; World Precision Instruments) using a programmable microelectrode puller (P-97; Sutter Instrument). Tip resistance ranged from 7.0 to $10.0 \mathrm{M} \Omega$ when filled with internal solution. A potassium gluconatebased internal solution was used for the following optical EPSC recordings (in $\mathrm{mM}$ ): 135 potassium gluconate, 5 EGTA, $0.5 \mathrm{CaCl}_{2}, 2 \mathrm{MgCl}_{2}, 10$ HEPES, $2 \mathrm{MgATP}$, and 0.1 GTP, with pH adjusted to 7.25 with Tris base and osmolarity adjusted to $290 \mathrm{mOsm}$ with sucrose. A cesiumbased internal solution was used for the following optical IPSC recordings (in mM): $120 \mathrm{CsCH}_{3} \mathrm{SO}_{3}, 20 \mathrm{HEPES}, 0.4$ EGTA, 2.8 NaCl, 5 TEA, 2.5 Mg-ATP, and 0.25 Na-GTP, at $\mathrm{pH} 7.25$ and $290 \mathrm{mOsm}$ with sucrose. Both internal solutions also contained QX314 (2 mM) for improved voltage control.

\section{Standard patch-clamp electrophysiology}

Neurons within brain slices were first visualized with infrared or visible differential interference contrast optics, followed in some cases by fluorescence microscopy to identify neurons expressing fluorescent proteins. Electrophysiology experiments were conducted using a Nikon Eclipse FN-1 or Scientifica SliceScope. A computer running PCLAMP 10 software was used to acquire whole-cell recordings along with a Multiclamp $700 \mathrm{~B}$ or Axopatch 200B amplifier and an analog-to-digital A/D converter (Digidata 1440A or Digidata 1550A). pCLAMP software, Multiclamp/Axopatch amplifiers, and Digidata A/D converters were from Molecular Devices. Data were sampled 
at $10 \mathrm{kHz}$ and low-pass filtered at $1 \mathrm{kHz}$. Immediately before gigaseal formation, the junction potential between the patch pipette and the superfusion medium was nulled. Series resistance was uncompensated. A light-emitting diode (LED) light source (XCite 110LED; Excelitas) coupled to an excitation filter (470/40 nm bandpass) was used to stimulate the preparation with light flashes. Light flashes were triggered by PCLAMP via transistor-transistor logic pulses. Flash energy output from the LED was determined by calibration using a photodiode power sensor (model S120C; Thorlabs). Optical pulse duration $(0.5-5 \mathrm{~ms})$ and flash strength $\left(0.01-0.1 \mathrm{~mW} / \mathrm{mm}^{2}\right)$ were empirically chosen for each cell such that baseline responses were initially $\sim 50-150 \mathrm{pA}$. Drugs were applied via bath superfusion. For our recording chamber (volume, $1 \mathrm{ml}$ ) and solution flow rate, we estimate that complete solution exchange occurs in 5-8 min.

\section{mRNA in situ hybridization and expression analysis}

Mice were deeply anesthetized with Euthasol and decapitated. Brains were quickly removed on ice, snap frozen, and embedded in cryoembedding medium (OCT). Brains were sectioned on a cryostat (CM3050; Leica) into $20 \mu \mathrm{m}$ sections, sections were adhered to Superfrost Plus slides, and kept at $-20^{\circ} \mathrm{C}$ to dry for $60 \mathrm{~min}$ and stored at $-80^{\circ} \mathrm{C}$ until use. Sections were fixed with $4 \%$ paraformaldehyde and processed for RNAscope [Advanced Cell Diagnostics (ACD; http://acdbio.com)] multichannel fluorescence in situ hybridization (FISH) according to the manufacturer manual for Multiplex assays. Sections were mounted with ProLong Gold Antifade Mountant with DAPI (Thermo Fisher Scientific). Probes for the detection of specific targets (Chrnb2, Gad2, VGluT2 [S/c17a6]) were purchased from ACD.

Sections were imaged on a Nikon A1 confocal microscope according to the following parameters: $1024 \times$ 1024 pixels, $\sim 200 \mathrm{~nm} /$ pixel, and $20 \times 0.75$ numerical aperture objective. Nikon system images were processed with custom scripts in ImageJ $(\mathrm{NIH})$. All images to be used for FISH quantification were acquired and processed in the same manner. FISH quantification used the "fluorescence coverage (\%)" method, which reports the fraction of fluorescent pixels to total pixels in a cellular region of interest (ROI). An ImageJ script used DAPI staining to locate nuclei for automated and unbiased creation of cellular ROIs. The DAPI image was filtered with a Gaussian blur filter $(\sigma=3)$, thresholded (ImageJ "default" threshold), and the thresholded nuclei were dilated slightly (MorphoLibJ dilation filter; disk, radius $=2$ ) to allow the capture of the RNA fluorescence signal just outside the nucleus but still presumably within the cell. A watershed algorithm was then applied to the filtered, binary DAPI image to isolate/separate adjacent nuclei. Finally, ROls were detected in ImageJ (Analyze Particles algorithm; size $=20$ to infinity; circularity $=0.5-1.0$ ) and saved for application to fluorescence channel images. FISH channel images were each processed as follows: Gaussian blur filter $(\sigma=1)$; Mexican Hat filter (radius $=2$ ); and threshold (Otsu algorithm). ROls from the DAPI image routine were then applied to the filtered/thresholded FISH channel and a raw "percentage coverage" value was derived for each ROI. For each channel, these raw percentage coverage values for each $\mathrm{ROI}$ were then scaled to the single ROI in the dataset with the highest percentage coverage. This normalization step accounted for differences in probe performance and target gene expression levels. Using these transformed/normalized datasets, a cutoff value of $10 \%$ "normalized percentage coverage" was uniformly assigned to each distribution. A scatter plot shows this cutoff for each channel as a horizontal and vertical line at $10 \%$ normalized coverage. Exactly $n=3$ mice were sampled, and two images of the MVTA were analyzed per mouse.

\section{Statistics and data analysis}

The $\alpha$ level was set to 0.05 for all statistical tests, which were conducted with GraphPad Prism 7 (GraphPad Software). Null hypothesis statistical testing was used, where the null hypothesis stated, in general, that drug treatments have no effect on the physiologic measures being taken. We pooled all baseline (before nicotine treatment) responses to examine the underlying distribution of optical EPSC (oEPSC) and optical IPSC (oIPSC) amplitudes. Both were normally distributed, so parametric tests were selected for analysis. Statistical testing consisted either of one-tailed paired $t$ test (for paired samples with an expected effect direction) or repeated-measures ANOVA for three or more paired samples. For the latter, omnibus testing was conducted to determine whether an effect of treatment existed. When omnibus test results resulted in an $F$ statistic with an associated $p$ value $<0.05$, subsequent comparisons were made to identify which treatment group differences accounted for the overall main effect uncovered by the omnibus test. For such post hoc comparisons, specific comparisons were made instead of comparing all groups with all other groups. This choice necessitated using the Sidak multiple-comparisons test. Effect sizes and post hoc power determinations were conducted with $\mathrm{G} *$ Power 3.1 or R. Bootstrap 95\% confidence intervals (Cls) for the mean difference were determine in R using the "dabestr" package. Image analysis was performed with ImageJ $(\mathrm{NIH})$. Analysis of electrophysiology data were performed with Clampfit (Molecular Devices) and custom scripts written in MATLAB (MathWorks). Throughout the figure legends, the number of individual neurons tested is stated immediately before the number of animals from which those neurons were derived. Nicotine-mediated increases or decreases in oEPSC/oIPSC amplitude were assessed as follows. Several responses (typically, approximately four) were recorded and averaged before and after nicotine bath application. When this mean response after nicotine exceeded the pre-nicotine application mean, the cell was classified as having an increased response. Conversely, cells with a post-nicotine application mean that was less than the pre-nicotine application mean were classified as having a decreased response. No cells demonstrated an equal response before and after nicotine application. 
a

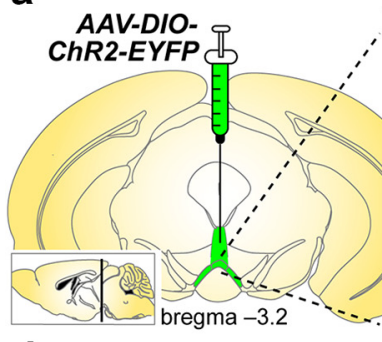

d

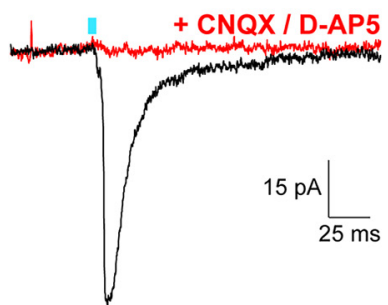

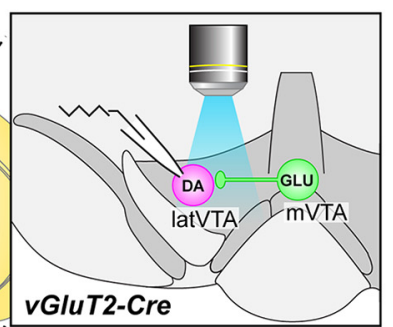

e

(i)

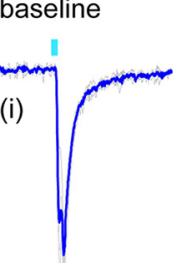

b

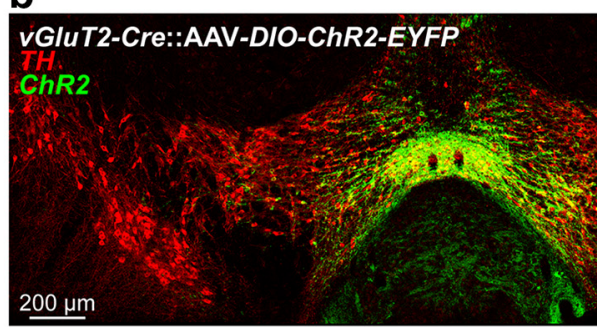

C

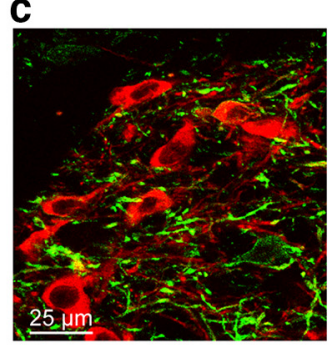

Figure 1. mVTA to latVTA glutamate transmission is monosynaptic. a, AAV-DIO-ChR2-EYFP vectors were unilaterally microinjected into mVTA of VGluT2-Cre mice to permit optical stimulation of mVTA terminals in latVTA. $\boldsymbol{b}$, TH/EYFP stain shows ChR2 expression in mVTA somata. $\boldsymbol{c}$, TH/EYFP stain in latVTA shows ChR2 expression from mVTA in terminals surrounding TH $^{+}$cells. $\boldsymbol{d}$, oEPSCs recorded in latVTA are sensitive to CNQX (10 $\mu \mathrm{m}) / \mathrm{D}-\mathrm{AP} 5(30 \mu \mathrm{M})$ application. e, An oEPSC trace family from a representative latVTA neuron is shown (gray, individual stimulation trials; blue, averaged trace). oEPSCs were measured at baseline (i) and following superfusion of the indicated drugs (ii-iv). $\boldsymbol{f}$, Summary before/after scatter plot for all cells studied as described in $\boldsymbol{e}$. $n=5$ neurons from 4 mice (1 male, 3 female).

\section{Results}

To study local glutamatergic circuits within the VTA, ChR2-enhanced yellow fluorescent protein (EYFP) was expressed in a Cre recombinase-dependent manner in medial VTA VGluT2 ${ }^{+}$neurons of VGluT2-Cre mice via microinjection of AAV vectors (Fig. 1a, left). Patch-clamp recordings were made in neurons of the latVTA, an area enriched in DA neurons (Lammel et al., 2008). ChR2expressing terminals in latVTA from mVTA-derived glutamate neurons were activated with full-field flashes $(\sim 470$ $\mathrm{nm}$; 0.01-0.1 $\mathrm{mW} / \mathrm{mm}^{2}$ ) through the $40 \times$ microscope objective (Fig. 1a, exploded right panel). We verified viral targeting of EYFP-tagged ChR2 in mVTA via anti-GFP immunohistochemistry; ChR2-EYFP was strongly expressed in mVTA (Fig. 1b). ChR2 was also targeted to axons/fibers that were intermingled with $\mathrm{TH}^{+}$DA neurons in latVTA (Fig. 1c). Using patch-clamp electrophysiology, we validated that ChR2 activation in MVTA-derived VGluT2 $^{+}$terminals led to glutamate release onto latVTA neurons. Robust oEPSCs were evoked with $\sim 470 \mathrm{~nm}$ light flashes, and oEPSCs were fully sensitive to bath application of ionotropic glutamate receptor antagonists (CNQX, $10 \mu \mathrm{M}$; D-AP5, $30 \mu \mathrm{M}$; Fig. 1d). The connection rate was high between mVTA VGluT2 ${ }^{+}$and latVTA neurons: $n=44$ latVTA neurons; $n=38$ exhibited oEPSCs. Synaptic responses typically exhibit $2-10 \mathrm{~ms}$ synaptic delay (Yan et al., 2018), whereas direct ChR2-mediated photocurrents do not. Recorded oEPSCs had a synaptic delay of $6.1 \mathrm{~ms}$ [SD $=2.5 ; n=20$ neurons, $n=12$ mice (7 male, 5 female)], confirming the synaptic nature of these responses. These results are the first to describe a high rate of excitatory connectivity between mVTA VGluT2 ${ }^{+}$and latVTA neurons.
Next, we asked whether mVTA-to-latVTA excitatory transmission is monosynaptic or polysynaptic. These can be distinguished by first blocking activity-dependent oEPSCs with TTX $(0.5 \mu \mathrm{M})$, followed by coapplication of TTX with $\mathrm{K}^{+}$channel blocker 4-AP $(100 \mu \mathrm{M})$. If connections are monosynaptic, 4-AP will typically surmount the TTXmediated block of oEPSCs. Last, CNQX/D-AP5 was applied to determine whether the responses were mediated by ionotropic glutamate receptors (Fig. 1e). In $n=5$ latVTA neurons, this treatment sequence resulted in a main effect of treatment $\left(F_{(1.551,6.205)}=23.05 ; p=0.0017\right.$; Table 1, "a" row), as indicated by a one-way repeatedmeasures ANOVA omnibus test on groups/conditions i-iii shown in Figure 1e. The CNQX/D-AP5 condition was not included in the statistical testing because this treatment was used as an exclusion metric; although there were no such cells, if a cell had been insensitive to CNQX/D-AP5, it would have been excluded from the analysis. Follow-up Sidak multiple-comparison testing indicated that TTX suppressed oEPSCs $(p=0.0083$; Table 1, "b" row; Fig. 1f), while TTX + 4-AP promoted the recovery of the oEPSC $(p=0.0028$; Table 1 , "c" row; Fig. 1f). These results demonstrate that mVTA-to-latVTA glutamate transmission is very likely to be monosynaptic.

Having isolated the activity of glutamatergic terminals from mVTA VGluT2 ${ }^{+}$cells, we next asked whether nAChR activation could modulate these monosynaptic excitatory synapses. To do this, oEPSCs recorded in latVTA neurons were first blocked by TTX and recovered with TTX + 4-AP. Nicotine (along with the continued presence of TTX + 4-AP) was then bath applied, followed by nicotine plus a nAChR antagonist cocktail (10 $\mu \mathrm{M} \mathrm{DH} \beta \mathrm{E}, 10 \mathrm{~nm}$ MLA). One-way omnibus ANOVA indicated no main effect of 
Table 1: Statistical table

\begin{tabular}{|c|c|c|c|c|c|c|}
\hline & Fig. & Data structure & Type of test & $p$ Value & Effect size $* *$ & $95 \% \mathrm{Cl}(\mathrm{pA})$ \\
\hline $\mathrm{a}$ & $1 f$ & Normal & One-way RM ANOVA & 0.0017 & 0.8521 & $\mathrm{n} / \mathrm{a}$ \\
\hline b & $1 f$ & Normal & Sidak post hoc & $0.0083 *$ & $-92.3 \mathrm{pA}$ & -37.8 to -146.8 \\
\hline c & $1 f$ & Normal & Sidak post hoc & $0.0028 *$ & $82.5 \mathrm{pA}$ & 119.0 to 46.0 \\
\hline d & $2 a$ & Normal & One-way RM ANOVA & 0.5454 & 0.0395 & $\mathrm{n} / \mathrm{a}$ \\
\hline e & $2 d$ & Normal & Paired $t$ test (one tailed) & 0.0019 & $14.5 \mathrm{pA}$ & 7.8 to 21.2 \\
\hline$f$ & $2 f$ & Normal & Paired $t$ test (one tailed) & 0.0032 & $-20.47 \mathrm{pA}$ & -32.2 to -8.7 \\
\hline g & $3 b$ & Normal & Paired $t$ test (one tailed) & 0.0065 & $14.55 \mathrm{pA}$ & 4.2 to 24.9 \\
\hline $\mathrm{h}$ & $3 d$ & Normal & Paired $t$ test (one tailed) & 0.2721 & $-1.45 \mathrm{pA}$ & -7.2 to 4.3 \\
\hline i & $5 f$ & Normal & One-way RM ANOVA & 0.0010 & 0.5563 & $\mathrm{n} / \mathrm{a}$ \\
\hline 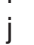 & $5 f$ & Normal & Sidak post hoc & $0.0000026 *$ & $-60.45 \mathrm{pA}$ & -43.1 to -77.9 \\
\hline k & $5 f$ & Normal & Sidak post hoc & $0.0051 *$ & $64.45 \mathrm{pA}$ & 107.8 to 21.1 \\
\hline | & $6 b$ & Normal & One-way RM ANOVA & 0.00000031 & 0.9384 & $\mathrm{n} / \mathrm{a}$ \\
\hline $\mathrm{m}$ & $6 b$ & Normal & Sidak post hoc & $0.000070 *$ & $-20.67 \mathrm{pA}$ & -15.1 to -26.3 \\
\hline$n$ & $6 b$ & Normal & Sidak post hoc & $0.000069 *$ & $16.79 \mathrm{pA}$ & 21.3 to 12.3 \\
\hline
\end{tabular}

Effect sizes and power were calculated with $\mathrm{G} *$ power 3.1. n/a, Not applicable; RM, repeated measures.

$*$ Multiplicity-adjusted $p$ value; $* *$ For RM ANOVA, effect size reported is $R^{2}=\mathrm{SS}_{\text {treatment }} /\left(\mathrm{SS}_{\text {treatment }}+\mathrm{SS}_{\text {residual }}\right)$; for Sidak test and paired $t$ test, effect size reported is the mean difference in $\mathrm{pA}$.

drug treatment $\left(F_{(1.054,10.54)}=0.4116 ; p=0.5454\right.$ Table 1, "d" row; Fig. 2a). However, when the before/after data were visualized on an $x-y$ plot with an associated unity line (Fig. $2 b$ ), it was clear that the effect of nAChR activation was bidirectional. In $n=5$ of 11 latVTA cells [ $n$ $=4$ mice (2 male, 2 female)], nicotine suppressed monosynaptic oEPSC amplitude (Fig. 2c, left and middle traces). In the other $n=6$ of 11 cells, nicotine-enhanced monosynaptic oEPSC amplitude (Fig. 2e, left and middle traces). To formally examine this bidirectional effect with null hypothesis statistical testing, it was not appropriate to assign cells to these specific subgroups based on the valence of their response to nicotine and to then follow this by statistical testing taking the null hypothesis of "no effect of nicotine." However, taking these subgroups as the reference point, we felt it appropriate to formally examine the effect of nAChR antagonist treatment compared with the "baseline" response in the presence of nicotine. In both the "nicotine decrease" and "nicotine increase" subgroups, nAChR antagonist cocktail treatment effectively increased $(t=6.001, \mathrm{df}=4, p=0.0019$, one-tailed paired $t$ test; Table 1, "e" row; Fig. 2d) or decreased $(t=4.479$, df $=5, p=0.0032$, one-tailed paired $t$ test; Table 1, "f" row; Fig. 2f) the oEPSC amplitude, respectively. It should be noted that this statistical analysis approach was not planned before the experiment, as the bidirectional effect of nicotine we uncovered was not anticipated. Overall, these data indicate that nicotine has complex effects on mVTA-to-latVTA glutamate transmission; depending on the recorded cell, nicotine either enhanced or suppressed local glutamate transmission.

Nicotine-mediated enhancement of oEPSCs in VTA microcircuits is consistent with prior work (Yan et al., 2018), but nicotine-mediated suppression of oEPSCs (Fig. 2c, d) has not been previously reported. Based on recent published work that established the corelease of glutamate and GABA from mVTA cells (Root et al., 2014b), we speculated that the nicotine-mediated suppression of oEPSCs could indicate the corelease of GABA from synaptic terminals derived from mVTA VGluT2 ${ }^{+}$neurons. To test this idea, a recording was made in latVTA and an oEPSC was evoked with a $\sim 470 \mathrm{~nm}$ light flash. Nicotine was then bath applied, allowing us to identify neurons based on subgroups presented in Figure 2. To determine whether nicotine application activated GABA release to mediate the suppression or enhancement in the oEPSC, PTX was coapplied with nicotine and the oEPSC amplitude was measured again (Fig. 3a,c). Via the same rationale as above (Fig. 2), we only formally examined the effect of PTX within each subgroup using null hypothesis statistical testing. PTX reversed the effect of nicotine in the nicotine decrease subgroup $(t=3.311$, $\mathrm{df}=7, p=$ 0.0065 , one-tailed paired $t$ test; Table 1 , " $g$ " row; Fig. $3 b$ ), but PTX had no effect in the nicotine increase subgroup ( $t$ $=0.6501, \mathrm{df}=5, p=0.2721$, one-tailed paired $t$ test; Table 1, "h" row; Fig. 3d). Coapplication of CNQX/D-AP5 with nicotine and PTX was sufficient to abolish the oEPSC (Fig. 3b,d), confirming that the oEPSC (post-nicotine/PTX application) was indeed mediated by glutamate release. The effect of CNQX/D-AP5 was not formally examined with statistical testing because this treatment was used as an exclusion metric; though there were none, if any cells had failed to respond to CNQX/D-AP5, they would have been eliminated from the analysis. Together, these results reveal bidirectional modulation of mVTA-to-latVTA glutamate transmission by nicotine, including the potential for nicotine-mediated boosting of GABA release from VGluT2 ${ }^{+}$axon terminals.

Within the two groups of latVTA cells we identified, namely those with a nicotine-mediated (1) oEPSC decrease and (2) oEPSC increase, we pooled responses from experiments shown in Figures 2 and 3 to conduct a subsequent analysis on effect size and its precision. In latVTA cells with a nicotine-mediated decrease in oEPSC amplitude, nicotine decreased the oEPSC amplitude by $-19.1 \mathrm{pA}$. Using bootstrap resampling, we calculated the $95 \%$ confidence interval for this effect as -23.7 to -14.6 . For latVTA cells where nicotine increased the oEPSC, the effect size and $95 \%$ confidence interval are 20.7 pA (95\% $\mathrm{Cl}, 15.7-26.8)$. 
a

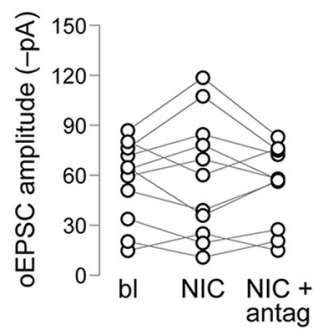

b

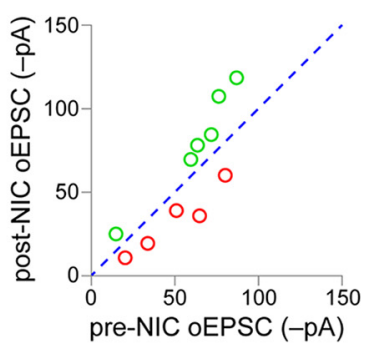

C

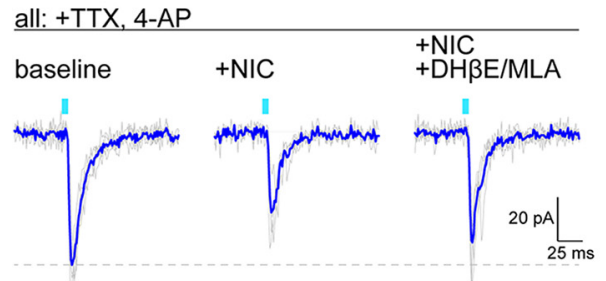

e

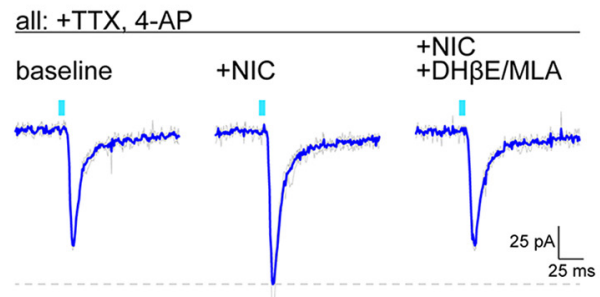

d

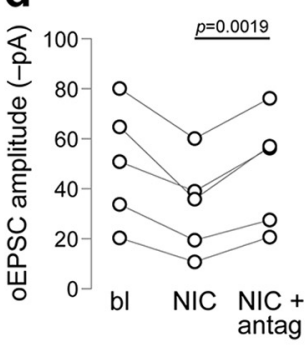

f

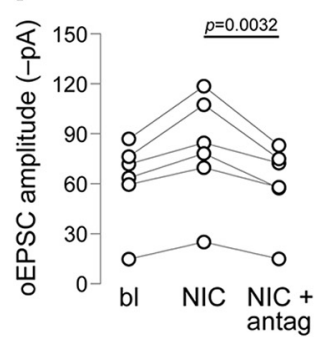

Figure 2. Nicotine modulation of monosynaptic mVTA-to-latVTA glutamate transmission. VGluT2 ${ }^{+}$, ChR2-bearing fibers from mVTA were stimulated during recordings from latVTA cells at baseline, after superfusion with nicotine $(0.3 \mu \mathrm{M})$, and following superfusion with nicotine $+\operatorname{Dh} \beta E+$ MLA. $\boldsymbol{a}$, Before/after plot summarizing all tested cells. $\boldsymbol{b}$, Baseline versus nicotine data from $\boldsymbol{a}$ are plotted on an $x-y$ plot where the blue dashed line indicates the unity line of no change. Open red circles indicate cells exhibiting a nicotine-mediated reduction, whereas open green circles indicate cells exhibiting a nicotine-mediated increase. $\boldsymbol{c}$, An oEPSC trace family is shown from a representative latVTA neuron exhibiting a nicotine-mediated decrease in oEPSC amplitude (gray, individual stimulation trials; blue, averaged trace). $\boldsymbol{d}$, Summary before/after scatter plot for all red data points indicated in $\boldsymbol{b}$. $n=5$ neurons from 4 mice ( 2 male, 2 female). e, An oEPSC trace family is shown from a representative latVTA neuron exhibiting a nicotine-mediated increase in oEPSC amplitude (gray, individual stimulation trials; blue, averaged trace). $\boldsymbol{f}$, Summary before/after scatter plot for all green data points indicated in $\boldsymbol{b}$. $n=6$ neurons from 5 mice ( 2 male, 3 female).

To address the possibility of GABA release from terminals derived from VGluT2 ${ }^{+}$mVTA neurons, the coexpression of VGluT2 and Gad2 mRNA was examined in mVTA neurons using a quantitative RNA fluorescence in situ hybridization approach. In mVTA, we noted neurons that exclusively expressed VGluT2, neurons that exclusively expressed Gad2, and neurons that coexpressed these markers (Fig. 4a). Examination of VGluT2 and Gad2 normalized percentage coverage (a measure of transcript expression level) using a scatter plot revealed a minor but substantial subpopulation of mVTA neurons that express both markers (Fig. 4b). Quantification of coexpression confirmed that $n=117$ of 273 VGluT2 $^{+}$neurons also expressed Gad2 (Fig. 4c). Interestingly, nearly all mVTA VGluT2 ${ }^{+} / \mathrm{Gad}^{+}$neurons coexpressed Chrnb2 ( $\beta 2$ nAChR subunit; Fig. $4 b, c)$, suggesting that nicotine can modulate glutamate and GABA corelease in mVTA to latVTA circuits.
Next, we asked whether nicotine is also capable of modulating mVTA-to-latVTA GABA transmission. Credependent AAVs directing expression of ChR2-EYFP were microinjected into the MVTA of Gad2-Cre mice, allowing optogenetic stimulation of ChR2-bearing GABAergic terminals in latVTA (Fig. 5a). Anti-GFP immunohistochemistry, coupled with anti-TH counterstaining, revealed strong ChR2 expression in mVTA (Fig. 5b). ChR2 expression was also induced in interpeduncular nucleus (IPN), consistent with previous reports of dense Gad2 expression in this structure (Zhao-Shea et al., 2013). In the latVTA of these animals, $\mathrm{TH}^{+}$neurons were intermingled with-but not costained with-ChR2-EYFP ${ }^{+}$GABAergic fibers (Fig. $5 c$ ). Optical activation of ChR2 during recordings from latVTA neurons induced robust outward currents that we refer to hereafter as olPSCs. These oIPSCs were sensitive to PTX (Fig. $5 d$ ) and exhibited a synaptic delay of $6.8 \mathrm{~ms}(\mathrm{SD}=$ 1.6), confirming synaptic release of GABA. The connec- 

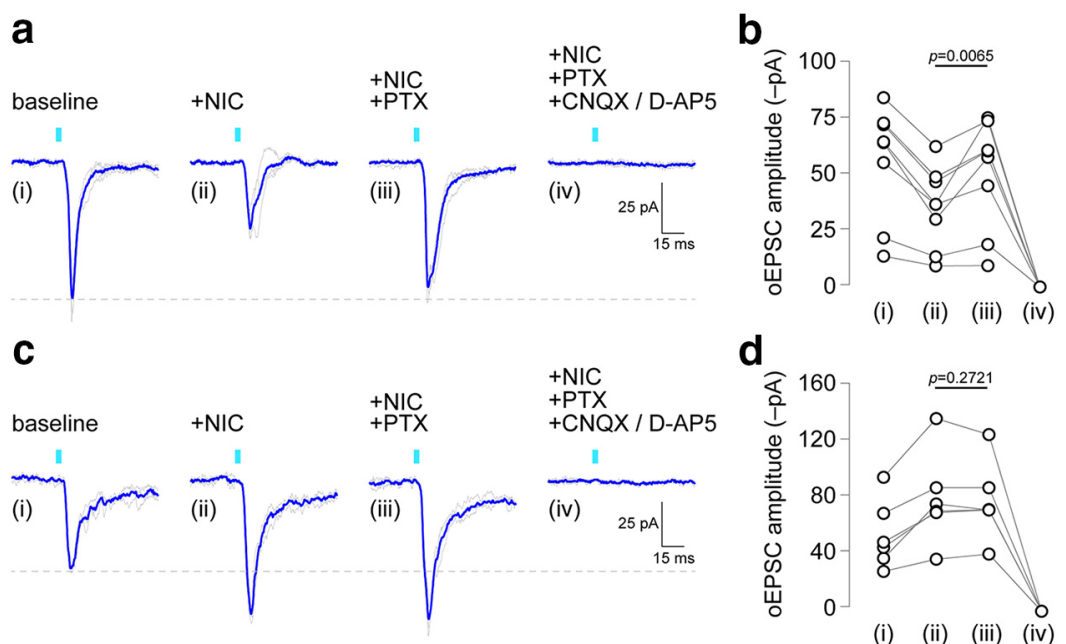

Figure 3. Nicotine-mediated suppression of oEPSCs occurs through GABA release. $a$, An oEPSC trace family from a representative latVTA neuron, which exhibited nicotine-mediated suppression of the oEPSC, is shown (gray, individual stimulation trials; blue, averaged trace). oEPSCs were measured at baseline (i), after superfusion of nicotine (0.3 $\mu \mathrm{M}$; ii), after nicotine plus PTX (50 $\mu \mathrm{M}$; iii), and after nicotine/PTX plus CNQX (10 $\mu \mathrm{M})$ and D-AP5 (30 $\mu \mathrm{M}$; iv). $\boldsymbol{b}$, Summary before/after scatter plot for all cells studied as described in a. $n=6$ neurons from 4 mice (2 male, 2 female). $\boldsymbol{c}$, An oEPSC trace family from a representative latVTA neuron, which exhibited nicotine-mediated enhancement of the oEPSC, is shown (gray, individual stimulation trials; blue, averaged trace). oEPSCs were measured at baseline (i), after superfusion of nicotine (0.3 $\mu \mathrm{m}$; ii), after nicotine plus PTX (50 $\mu \mathrm{m}$; iii), and after nicotine/PTX plus CNQX $(10 \mu \mathrm{M})$ and D-AP5 (30 $\mu \mathrm{M}$; iv). $\boldsymbol{d}$, Summary before/after scatter plot for all cells studied as described in $\boldsymbol{c}$. $n=8$ neurons from 6 mice (4 male, 2 female).

tion rate was high ( $n=31$ of 36 ) between mVTA GABAergic neurons and latVTA neurons.

To determine whether mVTA-to-latVTA GABA synaptic responses are monosynaptic or polysynaptic, we used the same pharmacological approach used for intra-VTA glutamate transmission. OIPSCs were blocked with TTX, then we attempted to recover them with coapplication of 4-AP with TTX before blockade of $\mathrm{GABA}_{A}$ receptors with PTX (Fig. 5e). In $n=13$ latVTA neurons, this treatment sequence resulted in a main effect of treatment $\left(F_{(1.211,14.53)}=15.05 ; p=0.0010\right.$; Table 1 , "i" row $)$, as indicated by a one-way repeated-measures ANOVA omnibus test. The PTX group was not included in the ANOVA because PTX sensitivity was used as an exclusion metric; PTX-insensitive responses would have been excluded from the analysis. Follow-up Sidak multiple-comparison testing indicated that TTX suppressed olPSCs $(p=$ 0.0000026; Table 1, "j" row), whereas 4-AP + TTX allowed olPSC recovery $(p=0.0051$; Table 1 , "k" row). PTX eliminated olPSCs in all cells tested (Fig. 5f). Normalizing the responses to pre-drug application levels (Fig. 5g) indicated that a majority of cells/responses could be fully recovered with 4-AP after TTX blockade (Fig. $5 g$, black symbols), but there were a minority of responses that did not recover (Fig. $5 \mathrm{~g}$, red symbols), suggestive of polysynaptic transmission in these cells. Nevertheless, these re- a

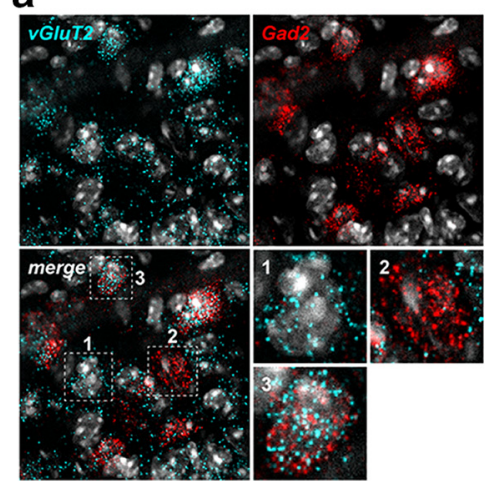

b

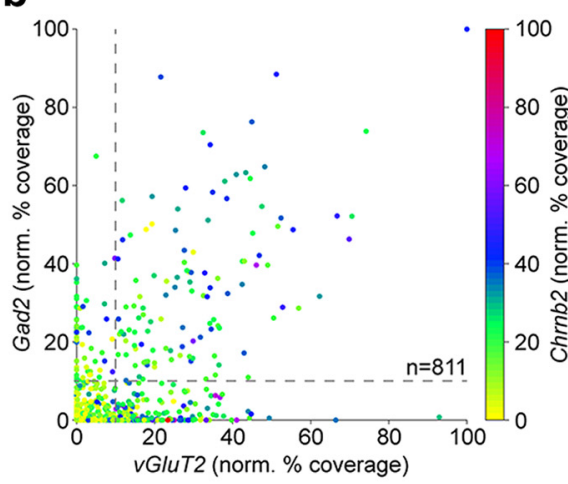

C
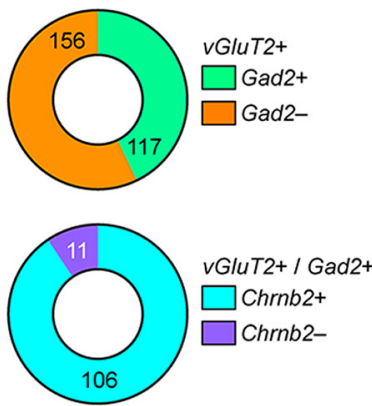

Figure 4. Coexpression of VGluT2 and Gad2 in mVTA. a, FISH in mVTA neurons for probes: VGluT2, Gad2. Individual, representative VGluT2 $^{+} / \mathrm{Gad}^{-}$(1), VGluT2 ${ }^{-} / \mathrm{Gad}_{2}{ }^{+}$(2), and VGluT2 ${ }^{+} / \mathrm{Gad}_{2}{ }^{+}$(3) cells are shown (images at bottom right). $\boldsymbol{b}$, Scatter plot of VGluT2 (abscissa) versus Gad2 (ordinate) normalized percentage of coverage for all nuclei in mVTA FISH images [ $n=3$ mice (1 male, 2 female)]. Chrnb2 normalized percentage of coverage for each nucleus is represented via the indicated dot color, as defined by the scale at right. c, Top, Pie graph of VGluT2 ${ }^{+}$nuclei showing the fraction of $\mathrm{Gad}_{2}^{+}$and Gad2 ${ }^{-}$nuclei. Bottom, Pie graph of VGluT2 $^{+} / \mathrm{Gad}^{+}{ }^{+}$nuclei showing fraction of $\mathrm{Chrnb}^{+}$and $\mathrm{Chrnb2}^{-}$nuclei. 
a

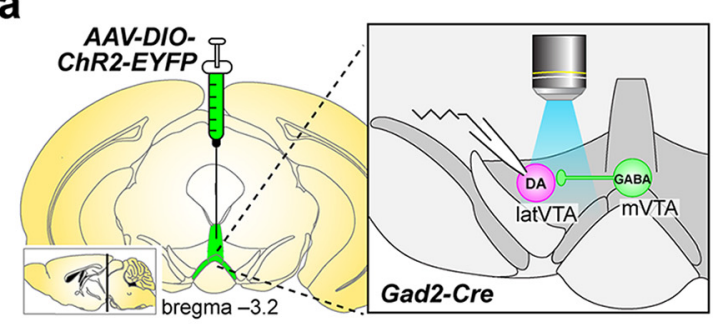

d

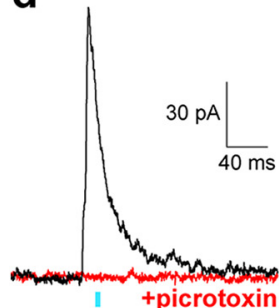

e

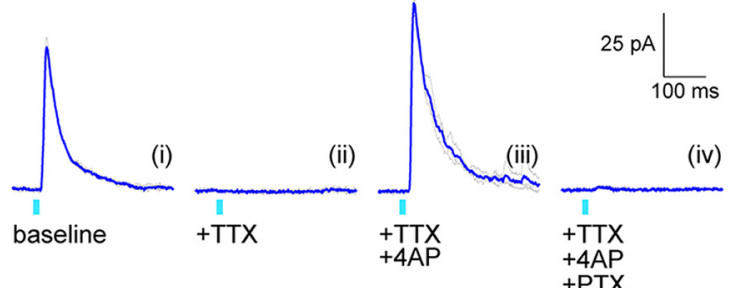

b

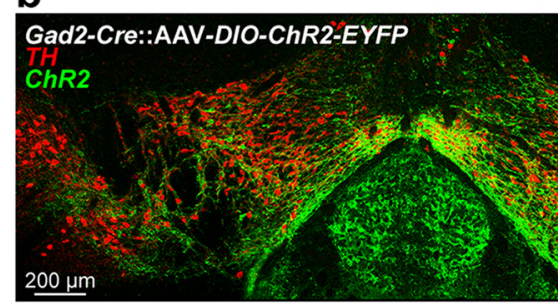

f

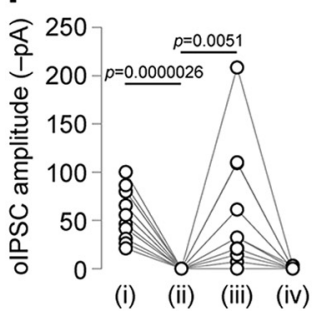

C
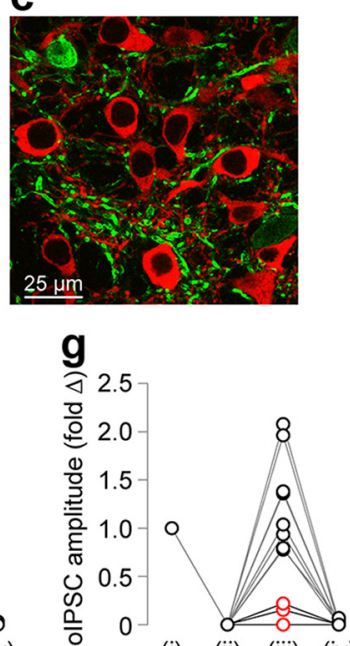

Figure 5. mVTA to latVTA GABA transmission is largely monosynaptic. a, AAV-DIO-ChR2-EYFP vectors were unilaterally microinjected into mVTA of Gad2-Cre mice to permit optical stimulation of mVTA terminals in latVTA. $\boldsymbol{b}$, TH/EYFP stain shows ChR2 expression in mVTA somata. $\boldsymbol{c}$, TH/EYFP stain in latVTA shows ChR2 expression from mVTA in terminals surrounding TH ${ }^{+}$cells. $\boldsymbol{d}$, Optical IPSCs recorded in latVTA are sensitive to PTX $(50 \mu \mathrm{m})$ application. $\boldsymbol{e}$, An olPSC trace family from a representative latVTA neuron is shown (gray, individual stimulation trials; blue, averaged trace). olPSCs were measured at baseline (i) and following superfusion of the indicated drugs (ii-iv). $\boldsymbol{f}$, Summary before/after scatter plot for all cells studied as described in $\boldsymbol{e}$. $n=12$ neurons from 7 mice (3 male, 4 female). $\boldsymbol{g}$, Data from $\boldsymbol{f}$ are shown normalized to their baseline responses. Data points in red indicate cells whose oIPSC was not recoverable with 4-AP following TTX treatment.

sults are broadly suggestive that mVTA GABA neurons directly synapse onto latVTA neurons and release GABA, activating $\mathrm{GABA}_{\mathrm{A}}$ receptors.

Finally, we studied nicotine modulation of mVTA-tolatVTA GABA transmission by isolating monosynaptic GABA responses in latVTA cells, followed by nicotine bath application, followed by bath application of nicotine plus nAChR antagonists (Fig. 6a). In $n=8$ cells, 7 cells exhibited a reduction in oIPSC amplitude following nicotine application, while 1 cell exhibited an increase in olPSC amplitude (Fig. 6b). In the following statistical analysis, the lone cell exhibiting a nicotine-mediated increase was excluded as an outlier after applying the ROUT method (Motulsky and Brown, 2006; maximum false discovery rate set to $1 \%$ ) to a data vector containing the difference between nicotine and baseline for the $n=8$ cell sample.
The treatment sequence shown in Figure 6a resulted in a main effect of treatment $\left(F_{(1.759,10.55)}=91.44 ; p=\right.$ 0.00000031 ; Table 1 , "l" row), as indicated by a one-way repeated-measures ANOVA omnibus test. Nicotine induced a reduction in oIPSC amplitude $(p=0.00007$; Table 1, "m" row), which was recoverable with coapplication of nicotine with a nAChR antagonist cocktail $(10 \mu \mathrm{M}$ $\mathrm{DH} \beta \mathrm{E}, 10$ nм MLA; $p=0.000069$; Table 1, "n" row; Fig. $6 b)$. These data suggest that the primary action of nicotine on mVTA-to-latVTA GABA transmission is to limit GABA release.

\section{Discussion}

Here, we report that mVTA-to-latVTA glutamatergic and GABAergic fast synaptic transmission are largely monosynaptic and exhibit strong/reliable connectivity. Smoking-relevant a

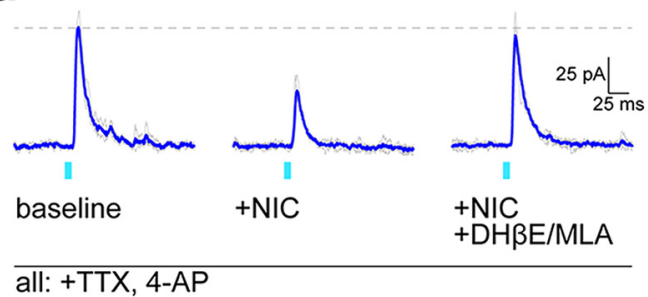

b

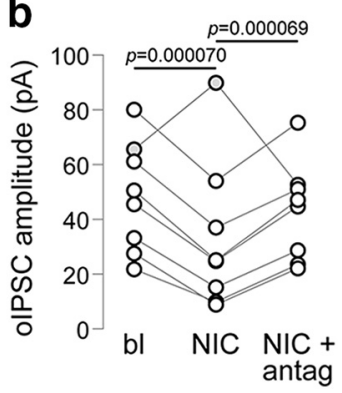

Figure 6. Nicotine modulation of monosynaptic mVTA to latVTA GABA transmission. $\boldsymbol{a}$, An olPSC trace family from a representative latVTA neuron is shown (gray, individual stimulation trials; blue, averaged trace). olPSCs were measured at baseline and following superfusion of nicotine, then nicotine $+\operatorname{Dh} \beta E+$ MLA. $\boldsymbol{b}$, Summary before/after scatter plot for all cells studied, as described in $\boldsymbol{a}$. The cell indicated by gray circles was excluded as an outlier from statistical analysis. $n=8$ neurons ( 1 of 8 excluded) from 6 mice ( 3 male, 3 female). 
concentrations of nicotine (300 nM) have differential effects on these systems; glutamate release is potentiated versus inhibited in approximately equal proportions, whereas GABA release is almost uniformly inhibited. Curiously, glutamate responses that are inhibited by nicotine show evidence of GABA corelease from VGluT2 ${ }^{+}$axons. Together, these results reveal a more complex system of VTA microcircuits than were previously understood. The actions of nicotine on these circuits are also complex, but collectively the data point to a net excitatory effect of nicotine on local fast synaptic transmission in the VTA.

\section{Physiology of local VTA circuits}

We sought to record local glutamatergic and/or GABAergic synaptic transmission in VTA DA neurons. The lateral VTA, defined mainly as lateral portions of the parabrachial pigmented nucleus, is composed largely of $\mathrm{TH}^{+}$ DA neurons that project mainly to the lateral shell of NAc (Lammel et al., 2008, 2011). Compared with other VTA neuron subtypes, latVTA neurons most closely resemble classical substantia nigra compacta (SNc) DA neurons (Lammel et al., 2008). Based on our recent work (Yan et al., 2018), we estimate that $65.6 \%\left(n=2100 \mathrm{TH}^{+}\right.$cells of 3203 total cells analyzed) of latVTA neurons are $\mathrm{TH}^{+} \mathrm{DA}$ neurons. Since this analysis was conducted on all nuclei in latVTA, which may include glial cells, this figure probably underestimates the prevalence of DA neurons relative to non-DA neurons in latVTA. Nevertheless, this indicates that a small minority of cells we recorded from in latVTA are likely to be non-DAergic. Our results indicate a high rate of connectivity between mVTA-derived fibers (glutamatergic or GABAergic) and latVTA somata/dendrites. For glutamatergic connections, this is consistent with a prior study that reported $100 \%$ connectivity between the recorded neuron and local VTA glutamatergic fibers (Yoo et al., 2016). Note, however, that this study did not specify the location within the VTA of the recorded neuron (e.g., mVTA, latVTA).

These results extend data reported previously and provoke new questions. Recently, it was demonstrated that NAc input to latVTA and mVTA neurons is primarily from the lateral versus the medial NAc shell, respectively (Yang et al., 2018). Reciprocal connections from VTA to NAc are similarly constrained into lateral or medial streams of information flow. In light of this apparent insulation of mVTA to medial NAc shell circuits from latVTA to lateral NAc shell circuits, how does the cross talk between mVTA and latVTA that we report modulate information flow between the VTA and forebrain targets like NAc or lateral habenula (Root et al., 2014a)? How does endogenous acetylcholine further modulate this cross talk? Subsequent studies will be required to address these issues.

\section{Nicotine modulation of local VTA circuits}

In this study, we show that nicotine concentrations relevant to tobacco consumption (300 nm; Matta et al., 2007) can bidirectionally modulate local glutamate release in mVTA-to-latVTA synaptic circuits. The overall effect sizes measured from pooled subgroup (nicotine-mediated excitation and suppression) data, along with their associated $95 \%$ confidence intervals calculated via bootstrap resampling, reveal a modest yet reliably consistent dual action of nicotine. Among synapses responding to nicotine with a decrease in oEPSC amplitude, the mean decrease was $19.1 \mathrm{pA}$ (decrease 95\% Cl, 14.6-23.7]. Considering the baseline amplitude, this amounts to a biologically meaningful reduction in glutamate release of $\sim 40 \%$. Likewise, responses to nicotine with the stimulation of glutamate release $(20.7 \mathrm{pA} ; 95 \% \mathrm{Cl}, 15.7-26.8)$ also point to a biologically meaningful $\sim 33 \%$ increase in glutamate release. Combined with a more uniform inhibition of mVTA-to-latVTA GABA release by nicotine, the net action of nicotine on local circuits impinging on latVTA could be excitatory; GABA release is dampened while glutamate release is reduced in $\sim 50 \%$ of latVTA cells and is enhanced in the other $\sim 50 \%$. This collective stimulation of latVTA by nicotine will presumably enhance burst firing in DA neurons (Mameli-Engvall et al., 2006) and stimulate DA release in NAc, contributing to the psychostimulant and rewarding properties of nicotine. This conclusion would be dependent, however, on the relative amount of local excitatory versus inhibitory innervation of latVTA neurons.

Using pharmacology coupled with whole-cell recordings, we demonstrate the definitive existence of presynaptic nAChRs in local mVTA-to-latVTA glutamate and GABA circuits. Although our usage of a $\beta 2$ and $\alpha 7 \mathrm{nAChR}$ antagonist cocktail in the present study precludes the determination of the nAChR subtype that modulates transmitter release, prior CRISPR (clustered regularly interspaced short palindromic repeats)-mediated knockdown of $\beta 2$ subunit expression suggests that heteromeric nAChRs play a key role (Yan et al., 2018). Does nicotine modulation of local VTA glutamate and GABA imply that endogenous $\mathrm{ACh}$ also modulates the release of these transmitters? Based on dramatically different pharmacokinetics/pharmacodynamics between nicotine in tobacco products and endogenous ACh (Wathey et al., 1979; Papke, 2014), the latter may not be as efficacious or potent at modulating fast transmitter release as the former.

Previous pioneering studies in VTA reported that the activation of presynaptic nAChRs enhances glutamate (Mansvelder and McGehee, 2000) or GABA (Mansvelder et al., 2002) release. By contrast, we found in VTA microcircuits that nicotine suppresses glutamate or GABA release in many neurons. These seemingly unexpected findings, compared with those of Mansvelder and McGehee (2000) and Mansvelder et al. (2002), likely relate to numerous methodological and anatomic differences. In particular, the following important parameters differed between our work and the work of Mansvelder and McGehee (2000) and Mansvelder et al. (2002): animal age and species (adult mouse vs early postnatal rat), slice orientation (coronal vs horizontal), presynaptic metric (optically evoked current vs spontaneous currents), and, most importantly, circuit specificity (genetically and pharmacologically targeted mVTA-to-latVTA transmission vs forebrainto-VTA transmission). Cell-specific manipulations and optogenetics were not available to Mansvelder and McGehee (2000) and Mansvelder et al. (2002) at the time 
of their important work, and it will be of interest to revisit those studies with current tools to further describe how cholinergic systems modulate neurotransmission in VTA.

What is the mechanism of nicotine-mediated suppression of glutamate and GABA release? We provide evidence supporting the following scheme: some mVTA neurons coexpress machinery for the synthesis of glutamate and GABA (Fig. 4), and nicotine stimulates a net increase in GABA release from these neurons onto latVTA target cells (Fig. 3). Corelease of glutamate and GABA has not previously been demonstrated in VTA microcircuits, but it has been shown for several other circuits whose somata reside in the VTA (Stuber et al., 2010; Stamatakis et al., 2013; Root et al., 2014a; Yoo et al., 2016). Coexpression of glutamate and GABA synthetic machinery has also been previously shown for mVTA neurons (Root et al., 2018; Mongia et al., 2019). Alternatively, it is possible that nicotine bath application causes the release of some unidentified factor that then inhibits or promotes fast transmitter release. Such a speculative mechanism would have to be activity independent, though, since our experiments with nicotine were performed in the continued presence of TTX. Prolonged exposure of VTA slices to nicotine could induce glutamate, GABA, and/or endocannabinoid release that could then act on mGluR, GABA $A_{B}$, or CB1 G-protein-coupled receptors to attenuate optical activation of VGluT2 ${ }^{+}$or Gad2 ${ }^{+}$fibers (Merrill et al., 2015; Han et al., 2017; Varani et al., 2018). It is very unlikely, however, that nicotine suppresses release by interfering with a stimulatory action of endogenous $\mathrm{ACh}$. If this were the case, nAChR antagonist application would not have reversed the action of nicotine (Figs. $2 d, 6 b$ ).

\section{Limitations and conclusions}

We isolated a specific microcircuit within the VTA, but this had limitations. Cre-dependent viral expression of ChR2 was directed to mVTA of VGluT2-Cre or Gad2-Cre mice, but the diffusion of virus to nearby brain areas is possible and would influence our results if those areas had VGluT2 ${ }^{+}$or Gad2 ${ }^{+}$neurons that projected to latVTA. ChR2 virus diffusion to nearby IPN and SNc is possible, but these areas are not known to send significant glutamatergic or GABAergic afferents to latVTA. Because we used Cre expression to induce opsins in certain cells, Cre was not available to help us unequivocally identify DA neurons in latVTA. Although DA neurons are enriched in latVTA, some latVTA neurons are not DAergic and a minor portion of our results may have come from such neurons. Although we report a high percentage of latVTA cells synaptically connected to mVTA neurons, our results may underestimate the true percentage; our ex vivo slicing procedure likely cannot induce a connection that was not present in vivo, but it may sever true connections to result in latVTA neurons that appear to be unconnected. We did not investigate the potential for latVTA-to-mVTA glutamate transmission due to a significantly lower percentage of VGluT2 ${ }^{+}$neurons in latVTA compared with MVTA (Taylor et al., 2014; Yan et al., 2018). Finally, conclusions about results derived from optogenetic isolation of circuits should be drawn with caution. ChR2 is an excellent tool for robust (and sometimes nonphysiologic) activation of neurons/circuits, but seemingly straightforward optogenetic results may produce a clearer picture of the underlying biology than actually exists.

In summary, this work adds to the important and emerging idea that nicotine modulates circuits wholly within the VTA in addition to afferents derived from outside the VTA. This reinforces the notion that nicotine has complex actions on VTA neurons and nAChRs, at both the somatodendritic and presynaptic location.

\section{References}

Centers for Disease Control and Prevention (2018) Current cigarette smoking among adults-United States, 2017. Morb Mortal Wkly Rep 67:1255-1232.

Corrigall WA, Coen KM, Adamson KL (1994) Self-administered nicotine activates the mesolimbic dopamine system through the ventral tegmental area. Brain Res 653:278-284.

Dobi A, Margolis EB, Wang HL, Harvey BK, Morales M (2010) Glutamatergic and nonglutamatergic neurons of the ventral tegmental area establish local synaptic contacts with dopaminergic and nondopaminergic neurons. J Neurosci 30:218-229.

Han X, He Y, Bi GH, Zhang HY, Song R, Liu QR, Egan JM, Gardner EL, Li J, Xi ZX (2017) CB1 receptor activation on VgluT2expressing glutamatergic neurons underlies $\Delta(9)$-tetrahydrocannabinol $(\Delta(9)$-THC)-induced aversive effects in mice. Sci Rep $7: 12315$

Hnasko TS, Hjelmstad GO, Fields HL, Edwards RH (2012) Ventral tegmental area glutamate neurons: electrophysiological properties and projections. J Neurosci 32:15076-15085.

Johnson SW, North RA (1992a) Opioids excite dopamine neurons by hyperpolarization of local interneurons. J Neurosci 12:483-488.

Johnson SW, North RA (1992b) Two types of neurone in the rat ventral tegmental area and their synaptic inputs. J Physiol 450: 455-468.

Lammel S, Hetzel A, Häckel O, Jones I, Liss B, Roeper J (2008) Unique properties of mesoprefrontal neurons within a dual mesocorticolimbic dopamine system. Neuron 57:760-773.

Lammel S, Ion DI, Roeper J, Malenka RC (2011) Projection-specific modulation of dopamine neuron synapses by aversive and rewarding stimuli. Neuron 70:855-862.

Lüscher C, Malenka RC (2011) Drug-evoked synaptic plasticity in addiction: from molecular changes to circuit remodeling. Neuron 69:650-663.

Mameli-Engvall M, Evrard A, Pons S, Maskos U, Svensson TH, Changeux JP, Faure P (2006) Hierarchical control of dopamine neuron-firing patterns by nicotinic receptors. Neuron 50:911-921.

Mansvelder HD, McGehee DS (2000) Long-term potentiation of excitatory inputs to brain reward areas by nicotine. Neuron 27:349357.

Mansvelder HD, Keath JR, McGehee DS (2002) Synaptic mechanisms underlie nicotine-induced excitability of brain reward areas. Neuron 33:905-919.

Maskos U, Molles BE, Pons S, Besson M, Guiard BP, Guilloux JP, Evrard A, Cazala P, Cormier A, Mameli-Engvall M, Dufour N, Cloëz-Tayarani I, Bemelmans AP, Mallet J, Gardier AM, David V, Faure P, Granon S, Changeux JP (2005) Nicotine reinforcement and cognition restored by targeted expression of nicotinic receptors. Nature 436:103-107.

Matta SG, Balfour DJ, Benowitz NL, Boyd RT, Buccafusco JJ, Caggiula AR, Craig CR, Collins AC, Damaj MI, Donny EC, Gardiner PS, Grady SR, Heberlein U, Leonard SS, Levin ED, Lukas RJ, Markou A, Marks MJ, McCallum SE, Parameswaran N et al. (2007) Guidelines on nicotine dose selection for in vivo research. Psychopharmacology 190:269-319.

Merrill CB, Friend LN, Newton ST, Hopkins ZH, Edwards JG (2015) Ventral tegmental area dopamine and GABA neurons: physiolog- 
ical properties and expression of mRNA for endocannabinoid biosynthetic elements. Sci Rep 5:16176.

Mongia S, Yamaguchi T, Liu B, Zhang S, Wang H, Morales M (2019) The ventral tegmental area has calbindin neurons with the capability to co-release glutamate and dopamine into the nucleus accumbens. Eur J Neurosci. Advance online publication. Retrieved November 20, 2019. doi:10.1111/ejn.14493.

Motulsky HJ, Brown RE (2006) Detecting outliers when fitting data with nonlinear regression-a new method based on robust nonlinear regression and the false discovery rate. BMC Bioinformatics $7: 123$.

Ngolab J, Liu L, Zhao-Shea R, Gao G, Gardner PD, Tapper AR (2015) Functional upregulation of $\alpha 4 *$ nicotinic acetylcholine receptors in VTA GABAergic neurons increases sensitivity to nicotine reward. J Neurosci 35:8570-8578.

Ntamati NR, Lüscher C (2016) VTA projection neurons releasing GABA and glutamate in the dentate gyrus. eNeuro 3:ENEURO. 0137-16.2016.

Papke RL (2014) Merging old and new perspectives on nicotinic acetylcholine receptors. Biochem Pharmacol 89:1-11.

Picciotto MR, Zoli M, Léna $C$, Bessis A, Lallemand $Y$, Le Novère $N$, Vincent P, Pich EM, Brûlet P, Changeux JP (1995) Abnormal avoidance learning in mice lacking functional high-affinity nicotine receptor in the brain. Nature 374:65-67.

Picciotto MR, Zoli M, Rimondini R, Léna C, Marubio LM, Pich EM, Fuxe K, Changeux JP (1998) Acetylcholine receptors containing the beta2 subunit are involved in the reinforcing properties of nicotine. Nature 391:173-177.

Qi J, Zhang S, Wang HL, Barker DJ, Miranda-Barrientos J, Morales M (2016) VTA glutamatergic inputs to nucleus accumbens drive aversion by acting on GABAergic interneurons. Nat Neurosci 19: 725-733.

Root DH, Mejias-Aponte CA, Qi J, Morales M (2014a) Role of glutamatergic projections from ventral tegmental area to lateral habenula in aversive conditioning. J Neurosci 34:13906-13910.

Root DH, Mejias-Aponte CA, Zhang S, Wang HL, Hoffman AF, Lupica CR, Morales M (2014b) Single rodent mesohabenular axons release glutamate and GABA. Nat Neurosci 17:1543-1551.

Root DH, Zhang S, Barker DJ, Miranda-Barrientos J, Liu B, Wang HL, Morales M (2018) Selective brain distribution and distinctive synaptic architecture of dual glutamatergic-GABAergic neurons. Cell Rep 23:3465-3479.

Stamatakis AM, Jennings JH, Ung RL, Blair GA, Weinberg RJ, Neve RL, Boyce F, Mattis J, Ramakrishnan C, Deisseroth K, Stuber GD (2013) A unique population of ventral tegmental area neurons inhibits the lateral habenula to promote reward. Neuron 80:10391053.
Stuber GD, Hnasko TS, Britt JP, Edwards RH, Bonci A (2010) Dopaminergic terminals in the nucleus accumbens but not the dorsal striatum corelease glutamate. J Neurosci 30:8229-8233.

Tan KR, Yvon C, Turiault M, Mirzabekov JJ, Doehner J, Labouèbe G, Deisseroth K, Tye KM, Lüscher C (2012) GABA neurons of the VTA drive conditioned place aversion. Neuron 73:1173-1183.

Taylor SR, Badurek S, Dileone RJ, Nashmi R, Minichiello L, Picciotto MR (2014) GABAergic and glutamatergic efferents of the mouse ventral tegmental area. J Comp Neurol 522:3308-3334.

Tolu S, Eddine R, Marti F, David V, Graupner M, Pons S, Baudonnat $M$, Husson $M$, Besson $M$, Reperant $C$, Zemdegs $J$, Pagès $C$, Hay YA, Lambolez B, Caboche J, Gutkin B, Gardier AM, Changeux JP, Faure P, Maskos U (2013) Co-activation of VTA DA and GABA neurons mediates nicotine reinforcement. Mol Psychiatry 18:382393.

van Zessen R, Phillips JL, Budygin EA, Stuber GD (2012) Activation of VTA GABA neurons disrupts reward consumption. Neuron 73: $1184-1194$.

Varani AP, Pedrón VT, Aon AJ, Höcht C, Acosta GB, Bettler B, Balerio GN (2018) Nicotine-induced molecular alterations are modulated by $\mathrm{GABA}_{\mathrm{B}}$ receptor activity. Addict Biol 23:230-246.

Wang HL, Qi J, Zhang S, Wang H, Morales M (2015) Rewarding effects of optical stimulation of ventral tegmental area glutamatergic neurons. J Neurosci 35:15948-15954.

Wathey JC, Nass MM, Lester HA (1979) Numerical reconstruction of the quantal event at nicotinic synapses. Biophys J 27:145-164.

Yan Y, Peng C, Arvin MC, Jin XT, Kim VJ, Ramsey MD, Wang Y, Banala S, Wokosin DL, Mclntosh JM, Lavis LD, Drenan RM (2018) Nicotinic cholinergic receptors in VTA glutamate neurons modulate excitatory transmission. Cell Rep 23:2236-2244.

Yang H, de Jong JW, Tak Y, Peck J, Bateup HS, Lammel S (2018) Nucleus accumbens subnuclei regulate motivated behavior via direct inhibition and disinhibition of VTA dopamine subpopulations. Neuron 97:434-449.e4.

Yoo JH, Zell V, Gutierrez-Reed N, Wu J, Ressler R, Shenasa MA, Johnson AB, Fife KH, Faget L, Hnasko TS (2016) Ventral tegmental area glutamate neurons co-release GABA and promote positive reinforcement. Nat Commun 7:13697.

Young-Wolff KC, Klebaner D, Folck B, Tan ASL, Fogelberg R, Sarovar V, Prochaska JJ (2018) Documentation of e-cigarette use and associations with smoking from 2012 to 2015 in an integrated healthcare delivery system. Prev Med 109:113-118.

Zhao-Shea R, Liu L, Pang X, Gardner PD, Tapper AR (2013) Activation of GABAergic neurons in the interpeduncular nucleus triggers physical nicotine withdrawal symptoms. Curr Biol 23:2327-2335. 